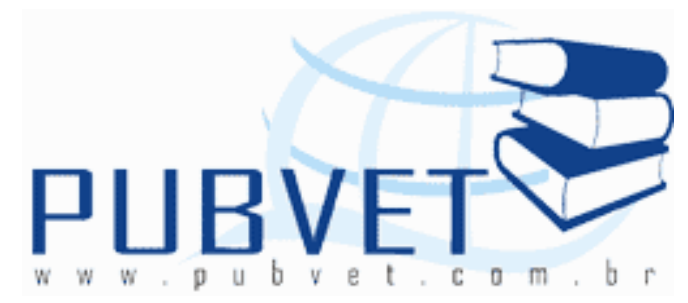

PUBVET, Publicações em Medicina Veterinária e Zootecnia.

\title{
Avaliação do comportamento de suínos em confinamento na fase de creche no Sul do Piauí
}

Aurino Araujo Rego Neto ${ }^{1}$, Gleyson Vieira dos Santos ${ }^{2}$, Edna Teles dos Santos ${ }^{2}$, Samily Ramos de Carvalhos ${ }^{3}$, Severino Cavalcante de Sousa Júnior ${ }^{4}$, Daniel Biagiotti $^{5}$, Natanael Pereira da Silva Santos ${ }^{5}$, Luciano Silva Sena²

${ }^{1}$ Discente do Programa de Pós-Graduação em Ciência Animal da UFPI, Teresina.

${ }^{2}$ Discente do Programa de Pós-Graduação em Zootecnia da UFPI/CPCE, Bom Jesus.

${ }^{3}$ Zootecnista formada pela UFPI/CPCE

${ }^{4}$ Professor, Doutor do Campus Cinobelina Elvas, Bom Jesus - UFPI.

${ }^{5}$ Aluno de Doutorado do Programa de Pós-Graduação em Ciência Animal da UFPI. Teresina-PI.

\section{Resumo}

Este trabalho teve como objetivo avaliar características comportamentais de 13 suínos da raça Ladrasse na fase de creche. Todos confinados, nas instalações do colégio agrícola da Universidade Federal do Piauí, no período de 22 a 29 de agosto de 2010, alimentados duas vezes ao dia. As observações dos suínos iniciaram às $8: 00 \mathrm{~h}$ e foram finalizaram às 20:00h, por dois dias 
consecutivos, com duração de $12 \mathrm{~h}$. As observações dos suínos apresentaram diferenças significativas $(P<0,05)$, para as características em pé, ócio e sentado quando comparadas com dias observados, também foram observadas diferenças significativas para o efeito de hora a característica ócio, e as características bebendo e sentado apresentaram diferenças quando avaliadas sob efeito animal.

Palavras-chave: Fase de Creche. Qui-quadrado. Comendo. Bebendo.

\title{
Assessment of the behavior of pigs in confinement in the nursery phase in southern Piauí
}

\begin{abstract}
This study aimed to assess the behavioral characteristics of 13 pigs breed Ladrasse the nursery phase. All confined on the premises of the college farm of the Federal University of Piauí, in the period from 22 to 29 August 2010, fed twice a day. The observations of pigs began at 8:00 am and were finished at 20:00 for two consecutive days, lasting $12 \mathrm{~h}$. The observations of the pigs showed significant differences $(P<0.05)$, for the characteristics standing and sitting idle when compared with days observed, were also significant differences in the effect of the characteristic leisure hours, and features sitting and drinking significantly different when evaluated under the influence animal.
\end{abstract}

Keywords: Phase Creche. Chi-square. Eating. Drinking.

\section{Introdução}

No Brasil, o agronegócio da suinocultura esta cada vez mais competitiva, principalmente quando comparadas com o mercado de carne bovina. A crescente demanda e a qualidade da carne suína, e uma das principais causas do aumento da produção brasileira. Contudo, para que o suinocultor possa atender a esta procura, ou ainda, aumentar a produção a baixo custo, com boa 
qualidade é essencial que se tenha um bom entendimento no que se refere ao comportamento dos animais, e não apenas a modernização de setores da produção animal como, a nutrição, genética e outras áreas que dizem respeito à produção animal (SILVA et al., 2007).

Segundo Machado Filho; Hotzel (2010), estudos de suínos, da região Nordeste brasileira devem ser realizados, com o intuito de reunir e correlacionar o maior número de informações possíveis sobre suas características produtivas e etológicas, tal como a capacidade adaptativa dessas espécies e suas condições climáticas no ambiente semiárido. Trabalhos que estudam características comportamentais ainda são insipientes em animais de produção e principalmente em sistemas intensivos de criação.

O estudo dos padrões de comportamento constitui uma ferramenta bastante utilizada no estudo da rotina da vida dos animais, pois é por meio deste que os animais se adaptam a diversos fatores ambientais, indicando potenciais métodos de melhoramento da produtividade animal com a utilização de diferentes manejos. Entretanto, a correta compreensão de um fenômeno envolve primeiramente o estudo da metodologia a ser utilizada bem como a escolha do intervalo para discretear as séries temporais.

O comportamento animal em regime de confinamento, é importante, pois possibilita o entendimento das variações no consumo de alimento e consequentemente na produção. No entanto, novas técnicas de alimentação modificam o comportamento alimentar e por seguinte o físico-metabólico, dos animais em confinamento (Armentano; Pereira, 1997). Portanto este trabalho objetivou avaliar o comportamento de leitões da raça Landrasse na fase creche, mantidos em sistemas de confinamento de criação na região do Vale do Gurguéia, no Sul do Estado do Piauí. 


\section{Material e métodos}

Os experimentos foram realizados no Setor de Suinocultura pertencente ao Colégio Agrícola da Universidade Federal do Piauí, Campus Professora Cinobelina Elvas (CPCE). Apresentando latitude de $9 \circ 6^{\prime} \mathrm{S}$, longitude de $44^{\circ} 7^{\prime}$ W e altitude de $331.74 \mathrm{~m}$, o clima da região é caracterizado como semi-árido, com temperatura do mês mais frio entre 15 e $20^{\circ} \mathrm{C}$ e temperatura do mês mais quente entre $34-37^{\circ} \mathrm{C}$, a pluviosidade menor que três $\mathrm{mm}$ durante o mês de realização do trabalho, segundo dados fornecidos pela estação meteorológica do campus CPCE, no período de agosto a setembro de 2010.

Para o estudo foram utilizados 13 leitões da raça Landrasse na fase de creche, pesando em média $10 \mathrm{~kg}$ cada animal com idades de dois meses e desmamados aos 15 dias de vida. O setor de suinocultura, onde foi conduzido o experimento, é todo de alvenaria, com pé direito de $3 \mathrm{~m}$, telhado com telhas de cerâmica, com uma baia específica para a creche, de dimensões $4,0 \mathrm{~m} \times$ $3,5 \mathrm{~m}$, com piso de cimento grosso havendo uma declividade para o escoamento dos dejetos, a baia era composta por um bebedouro pendular estilo chupeta e um cocho sob a chupeta para drenar a água residual e dois comedouros idênticos feitos com cano PVC de $300 \mathrm{~mm}$ fixados ao piso.

Os animais recebiam $500 \mathrm{~g}$ de ração por dia, fracionada em dois fornecimentos diários, pela manhã e à tarde. A composição nutricional da ração fornecida aos suínos está descrita na tabela 1 .

Tabela 1 - Composição nutricional da ração fornecida aos animais no período em que foram estudados

\begin{tabular}{lccccccc}
\hline Constituintes & $\mathrm{U}$ & $\mathrm{PB}$ & $\mathrm{EE}$ & $\mathrm{MF}$ & $\mathrm{MM}$ & $\mathrm{Ca}$ & $\mathrm{P}$ \\
Níveis nutricionais \% & 12,00 & 18,00 & 4,00 & 5,00 & 7,00 & 1,20 & 0,70 \\
\hline U-umidade, PR-proteina, Estrato etéreo, MF - matéria fibrosa, Matéria mineral, \\
Ca - cálcio, P-fosforo.
\end{tabular}


As avaliações dos suínos foram realizadas em dois dias consecutivos, das 08:00h às 20:00h, com duração de $12 \mathrm{~h}$ diárias totalizando 144 observações por animal.

No estudo as observações foram realizadas com intervalo de dez minutos conforme a maioria dos trabalhos encontrados na literatura, os dados referentes às atividades de comportamento de cada animal foram anotados em planilhas individuais por dois observadores treinados, mantidos em sistema de revezamento, posicionados de modo a não incomodar os animais, tendo todo o cuidado para que o local permanecesse o mais natural possível, evitando movimentos bruscos que pudessem alterar a situação natural existente do ambiente.

As características comportamentais observadas foram: em pé, deitado, explorando, cheirando, bebendo, comendo, ócio, fuçando, excretando, sentado, brincando e andando. Os dados obtidos foram tabulados e submetidos à análise de variância com o auxílio do procedimento npar1way do SAS 9.1 (1989), e foi utilizado o teste de $x 2$ (chi-quadrado) para as comparações das características.

\section{Resultados e discussão}

Os animais observados apresentam comportamento social normal com a necessidade de interagir com outros animais formando grupos isolados. Desta maneira os mesmos apresentam uma hierarquia social, embora à vida em grupo no ambiente natural traga uma serie de vantagens como defesa contra predadores, facilidade de encontrar parceiro sexual, busca por um ambiente com condições adequadas (Machado Filho; Hötzel, 2010). Os animais passaram parte do tempo em pé, apresentando diferença significativa deste comportamento nos dias avaliados o que difere das características do sistema de confinamento. 
Com relação ao estudo das características comportamentais dos suínos, nas características deitado, explorando e brincando não foram verificadas diferenças para os três efeitos comparativos, que foram; dias, horas e efeito de animal, isso indica que os leitões permaneceram o mesmo tempo realizando estas atividades nos dias de observações, o que mostra que os suínos que vivem em confinamento apresentam um comportamento dócil, pois os mesmos ficam uma considerável parte do tempo deitados ou em atividades rotineiras da espécie (Tabela 2).

Tabela 2 - Teste de significância $(P>0,05)$ para características comportamentais de suínos

\begin{tabular}{lllllll}
\hline Características & Dias & Horas & Animal & $\begin{array}{l}\text { Frequência } \\
(\%)\end{array}$ & CV(\%) & $\begin{array}{l}\text { DP } \\
(\%)\end{array}$ \\
\hline Em pé & $0.0175^{*}$ & $0.7258^{\text {n.s }}$ & $0.1007^{\text {n.s }}$ & 10,01 & 326.65 & 0.28 \\
Deitado & $0.8979^{\text {n.s }}$ & $0.1695^{\text {n.s }}$ & $0.4181^{\text {n.s }}$ & 53,00 & 93.93 & 0.49 \\
Explorando & $0.7913^{\text {n.s }}$ & $1.0000^{\text {n.s }}$ & $0.1306^{\text {n.s }}$ & 18,00 & 734.62 & 0.13 \\
Cheirando & $0.2714^{\text {n.s }}$ & $0.7231^{\text {n.s }}$ & $0.7626^{\text {n.s }}$ & 0,32 & 1842.82 & 0.05 \\
Bebendo & $0.8962^{\text {n.s }}$ & $0.8956^{\text {n.s }}$ & $0.0037^{*}$ & 5,16 & 425.97 & 0.22 \\
Comendo & $0.3981^{\text {n.s }}$ & $0.0680^{\text {n.s }}$ & $0.4280^{\text {n.s }}$ & 19,30 & 199.83 & 0.40 \\
Ócio & $0.0132^{*}$ & $0.0265^{*}$ & $0.2515^{\text {n.s }}$ & 1,90 & 874.37 & 0.11 \\
Fuçando & $0.1986^{\text {n.s }}$ & $0.7258^{\text {n.s }}$ & $0.4575^{\text {n.s }}$ & 0,11 & 1098.70 & 0.02 \\
Excretando & $0.9146^{\text {n.s }}$ & $0.7231^{\text {n.s }}$ & $0.7573^{\text {n.s }}$ & 0,84 & 4126.74 & 0.09 \\
Sentado & $0.0164^{*}$ & $0.7382^{\text {n.s }}$ & $0.0474^{*}$ & 0,53 & 967.81 & 0.10 \\
Brincando & $0.5109^{\text {n.s }}$ & $0.8108^{\text {n.s }}$ & $0.1469^{\text {n.s }}$ & 2,32 & 680.68 & 0.14 \\
Andando & $0.6405^{\text {n.s }}$ & $0.7824^{\text {n.s }}$ & $0.6667^{\text {n.s }}$ & 2,42 & 614.22 & 0.15 \\
Outros & $<.0001^{*}$ & $0,7824^{\text {n.s }}$ & $0.5858^{\text {n.s }}$ & 10,22 & 349.40 & 0.26 \\
\hline
\end{tabular}

*Significativo a $(P>0,05)$, ns = não significativo 
Resultados semelhantes foram descritos por Leite et al. (2006) estudando o comportamento de 36 suínos machos, castrados, em fase de terminação de suínos submetidos a diferentes sistemas de pastejo com livre acesso à ração.

Dentre as características comportamentais estudadas em leitões na fase de creche, as mais importantes para a produção animal são comendo e bebendo. A característica comendo não apresentou variação significativa quando relacionada dentro de horas, dias e animais, sendo assim, não existiu diferenças deste comportamento no período avaliado, indicando que os leitões estão se alimentando todos os dias na mesma hora, no mesmo período do dia e o mais importante, todos os animais juntos, de maneira homogenia. E ainda foi possível verificar na Figura 1, que o segundo comportamento mais realizado pelos leitões na fase de creche durante o experimento foi justamente, comendo, o que leva a crer que o manejo adotado na creche em questão apresenta-se adequado ao comportamento dos animais estudados.

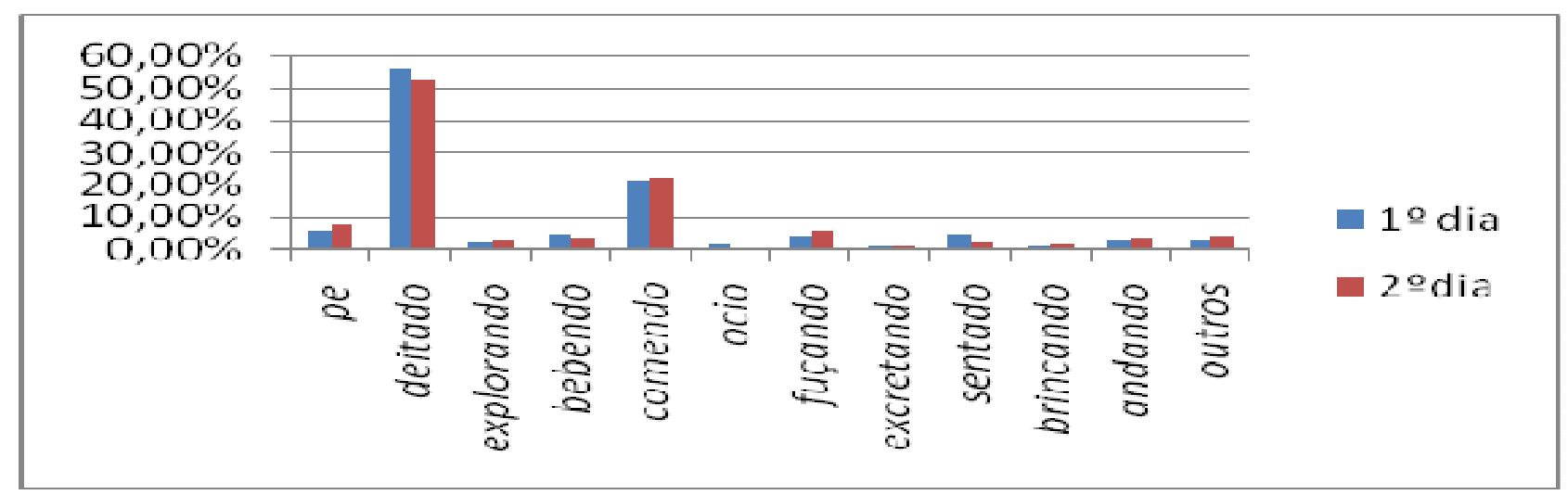

Figura 1- Frequências das características comportamentais de suínos, em relação aos dias estudados.

Na característica bebendo em leitões, foi verificada diferença significativa quando a característica foi comparada entre os animais observados (Tabela 2), já para horas e dias não foi obtida significância. A diferença obtida na 
frequência no consumo de água dentro de animais indica que os leitões frequentaram os bebedouros nos mesmos dias e horas, porém os animais beberam água separadamente, ou em pequenos grupos, de maneira heterogênea, com maior frequência próxima ao meio dia, compreendendo o período após a alimentação (Figura 1). Paiano et al. (2007) testou o comportamento de 32 suínos, confinados, e observou que houve diferença significativa para o tempo que os animais destinaram ao consumo de água, como maior frequência para os períodos da manhã e tarde, já Brum Jr. et al, (2010) avaliando suínos na fase de creche obteve resultados semelhantes aos aqui relatados.

Como os suínos confinados são animais que tem alimentação à vontade, os mesmos demonstraram que consomem ração em uma mesma quantidade e um mesmo período de tempo, independendo do sexo (Figura 1). Para a característica ócio foi verificada a significância para horas e dia das observações, indicando que os suínos na fase de creche apresentam comportamento dócil em sua maioria na maior parte do tempo, isso pode ser devido à recente separação destes animais de suas mães, ou seja, não estão totalmente adaptadas às condições de creche, e em alguns momentos mostrando-se inquietos, mesmo que passando maior parte do tempo deitados ou sentados, resultados semelhantes foram relatados por Silva et al. (2007); Campos et al. (2009) e Brum Jr. et al. (2010).

Para a característica sentada, ocorreu diferença significativa para os efeitos de dia e animal, os animais passaram algum tempo sentados o que é normal para suínos, porém em relação às horas do dia não ocorreu significância para esse efeito, não existindo uma hora do dia em que os animais estivessem sentados, mesmos resultados foram descritos por Paiano et al. (2007) e Brum Jr. et al. (2010). 
Os leitões na fase de creche estão se adequando aos manejos e a rotina diária de um confinamento, talvez devido a isso a algumas características, já mencionadas não apresentaram nenhuma significância em relação aos efeitos estudados (Machado Filho; Hötzel, 2010).

\section{Conclusões}

Os comportamentos dos leitões estudados estão dentro da normalidade para a fase em questão, pois o esperado nesse sistema de criação, é que os animais gastem o mínimo de energia e ganhem o máximo de peso no menor tempo possível.

\section{Referências}

ARMENTANO, L. e PEREIRA, M. Measuring the effectiveness of fiber by animal response trials. Journal of Dairy Science. 80: 1416-1425. 1997

Brum, JR, B. S. et al. Comportamento alimentar de leitões em fase final de creche. Anais XVI Congresso de Iniciação Científica da UFPEL, 27-29 nov., Pelotas, RS. CD-ROM. 2010.

CAMPOS, J.A.. Bem-estar de suínos confinados associados a comportamento, sistema imunológico e desempenho. Tese apresentada a Universidade federal de Viçosa, Minas Gerais. 79p. 2009.

LEITE, D. M. G., et al. Comportamento de suínos submetidos a diferentes sistemas de pastejo em pastagem de trevo-branco. Revista Brasileira Zootecnia. 35(4) 1774-1779. 2006.

MACHADO FILHO, L. C. P., HÖTZEL, M. J. Bem-Estar dos Suínos. Acessado às 16:34 do dia 9 de dezembro.Disponível em: htpp:/www.porksword.com.br. 2010.

PAIANO, D., BARBOSA, O. R., MOREIRA, I., BONET, A. R. Comportamento de suínos alojados em baias de piso parcialmente ripado ou com lâmina d’água. Acta Science Animal Science Maringá. 29(3) 345-351. 2007.

Sas Institute. 1989. SAS. user's guide: statistics. SAS Institute Inc., Cary, NC.

SILVA, O. K., et al. Medidas do ambiente acústico em creche de suínos. Revista Brasileira Engenharia Agrícola Ambiental. 11(3) 339-344. 2007. 